\title{
浙江印支期铝质 A 型花岗岩的发现及其地质意义
}

\author{
李万友 ${ }^{(1)} ，$ 马昌前 ${ }^{(1) *}$, 刘园园 ${ }^{\mathbb{1}}$, Paul T. ROBINSON ${ }^{\circledR}$
}

(1) 中国地质大学地球科学学院, 武汉 430074;

(2) 广东省地质局 706 地质大队, 韶关 512030 ;

(3) 中国地质大学地质过程与矿产资源国家重点实验室, 武汉 430074

* 联系人, E-mail: cqma@cug.edu.cn

收稿日期: 2011-03-04; 接受日期: 2011-09-15

国家科学技术部国际合作项目(编号: 2007DFA21230)、湖北省自然科学基金重点项目(编号: 2009CDA004)、国家自然科学基金创新群体 基金和重点项目(批准号: 40821061, 40334037)、教育部和国家外国专家局高等学校学科创新引智计划(编号: B07039)和地质矿产调查评价 专项(编号：基[2010]矿评 01-17-05)资助

\begin{abstract}
摘要 对浙西南靖居正长花岗岩开展了锆石 LA-ICP-MS U-Pb 年代学及岩石地球化学研究. 锆石年代学研究表明，靖居正长花岗岩的结晶年龄为 $(215 \pm 2) \mathrm{Ma}$, 表明其为一晚三叠世岩体, 而非前人所认为的白严纪岩浆活动产物. 靖居正长花岗岩具高的 $\mathrm{K}_{2} \mathrm{O}$ 和 $\mathrm{FeO}$ *含量和低的 $\mathrm{MgO}$ 含量，富集 $\mathrm{K}, \mathrm{Th}, \mathrm{La}, \mathrm{Ce}$ 等大离子亲石元素及轻稀土元素，亏损 $\mathrm{Nb}, \mathrm{Ta}, \mathrm{Ti}$ 等高场强元素，具高 的 $10^{4} \mathrm{Ga} / \mathrm{Al}$ 比值及 $(\mathrm{Zr}+\mathrm{Nb}+\mathrm{Ce}+\mathrm{Y})$ 含量, 岩石中出现自形的石英和他形的黑云母, 具有 $\mathrm{A}$ 型花 岗岩的特征. Sr-Nd 同位素研究结果显示, 岩石具有高的 $I_{\mathrm{Sr}}(0.7179 \sim 0.7203)$ 、低的 $\varepsilon_{\mathrm{Nd}}(t)$ (-14.2 -13.2)和较古老的 $T_{2 \mathrm{DM}}$, 与华夏地块古老的基底变质岩系特征一致, 指示岩浆来源于华 夏基底岩系. 研究认为, 靖居正长花岗岩是华夏古老的变质基底在伸展的构造背景下部分熔融 的产物. 靖居印支期 A 型花岗岩的确定, 为华南构造-岩浆演化带来新的时空约束, 对理解和构 建中国东南乃至华南地区早中生代构造演化具有重要意义.
\end{abstract}

关键词

印支期

年代学

地球化学

A 型花岗岩

浙江
关于华南中生代的构造转换时限, 主要存在两 种观点: 一是华南在早中侏罗世完成从古特提斯构 造域到太平洋构造域的转换 ${ }^{[1-3]}$; 二是印支期(晚二叠 世-早三叠世)古太平洋板块已经向华南陆块下俯

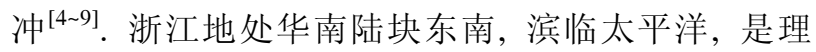
解华南构造演化的关键地带, 该区早中生代岩浆岩 的发现, 为解决华南地质演化问题提供了新的机会.

华南中生代花岗岩极为发育, 与此密切相关的 是大规模的成矿作用. 周新民 ${ }^{[10]}$ 、孙涛等 ${ }^{[11]}$ 统计显示, 中生代花岗岩以燕山期为主; 印支期岩体分布局限, 且多分布在厦门-常德一线西南. 近年来, 随着高精
度同位素年龄的不断报道，原先认为是加里东期和 燕山期的一些岩体陆续被确定为印支期，也有少部 分其他时代的花岗岩被误定为印支期岩浆作用产 物 ${ }^{[12 ~ 14]}$. 最新的统计结果 ${ }^{[2,15]}$ 显示, 华南印支期花岗 岩的出露面积仅相当于燕山期的近 $1 / 5$.

以往报道的印支期花岗岩，主要分布于桂东南、 湖南、赣南、粤北、海南及闽西等地区. 近来，闽北 铁山、洋坊正长岩 ${ }^{[4,5]}$ 及赣西蒙山花岗岩 ${ }^{[16]}$ 等印支期 岩体的发现，表明华南印支期岩浆活动要比以往认 识的强烈得多，但在浙江境内还罕有印支期岩浆活 动的可靠年龄报道. 本文拟对在浙西南靖居花岗岩

英文引用格式: Li W Y, Ma C Q, Liu Y Y, et al. Discovery of the Indosinian aluminum A-type granite in Zhejiang Province and its geological significance. Sci China Earth Sci, 2012, 55: 13-25, doi: 10.1007/s11430-011-4351-6 
体中新发现的印支期 A 型花岗岩进行详细报道, 并 讨论其地质意义.

\section{1 地质背景}

华南陆块由扬子地块和华夏地块组成. 扬子地 块周缘发育强烈的新元古代岩浆活动, 还出露有崆 岭杂岩等古老的基底岩石. 华夏地块也有早前寒武 纪的结晶基底出露, 主要分布于浙西南-闽西北地区, 包括八都群、陈蔡群、龙泉群三套岩石单元 ${ }^{[17 ~ 20]}$. 浙 西南地区尤以八都群分布最为广泛, 代表性变质岩 石是黑云斜长变粒岩、云母(石英)片岩、斜长角闪岩、 黑云斜长片麻岩, 显生宙主要经历过加里东期高角 闪岩相变质作用和印支期角闪岩相变质作用 ${ }^{[21,22]}$.

浙西南靖居花岗岩体位于汇山-绍兴深大断裂带 南东侧之龙泉-宁波隆起区内, 北东向龙泉-新建断裂 (F1)中段与北西向遂昌-山门断裂(F2)交汇处, 是一个 多期次侵入形成的复式岩体, 出露面积约 $50 \mathrm{~km}^{2}$. 岩 体展布受遂昌一山门断裂与龙泉-新建断裂联合控制, 呈 NE 向, 侵位于古元古代八都群黑云斜长片麻岩中, 岩体外围广泛分布早白严纪大爽组火山岩(图 1(b)).

根据野外接触关系, 浙江省第七地质大队 ${ }^{1}$ 将靖 居岩体主体分为三期: 第一期称鲁峰单元, 岩性为斑 状石英二长岩; 第二期称象溪单元, 岩性为中-细粒 正长花岗岩; 第三期为山背单元, 岩性为中粗粒正长 花岗岩; 晚期还有石英斑岩、花岗斑岩小岩株及岩脉.

经过详细的野外地质调查和室内研究, 我们发 现: 以往所定的第二期中-细粒正长花岗岩为二云母 花岗岩, 多成透镜体形式出现于岩体中, 其锆石 $\mathrm{U}-\mathrm{Pb}$ 年龄为 $(1880 \pm 32) \mathrm{Ma}$ (未发表的资料), 为古元古 代岩浆活动产物; 石英二长岩与正长花岗岩为靖居 岩体主体, 其中石英二长岩的铅石 $\mathrm{U}-\mathrm{Pb}$ 年龄为 $(233.7 \pm 1.8) \mathrm{Ma}$ (未发表的资料), 正长花岗岩锆石 $\mathrm{U}-\mathrm{Pb}$ 年龄为 $(215 \pm 2) \mathrm{Ma}$. 年龄数据与野外关系吻合.

本文重点报道的靖居花岗岩体第三期山背单元, 主要岩石类型为中粗粒正长花岗岩(后文称靖居正长 花岗岩), 部分可过渡至石英正长岩, 主要分布于靖 居复式岩体东南部, 东面受南北向断裂(F3)控制, 南 部零星出露, 被早白严纪大爽组火山岩覆盖, 深部可
能存在隐伏岩体. 靖居正长花岗岩为半自形粒状结 构, 块状构造; 主要矿物为钾长石、石英, 含少量斜 长石、黑云母及角闪石, 副矿物主要为褐帘石、磁铁 矿、磷灰石和铅石等. 碱性长石含量约 40\% 65\%, 主 要为微斜长石、条纹长石, 微斜长石发育格子双晶, 局部可见到微斜条纹长石; 石英含量约 10\% 35\%, 可见呈自形晶出现在岩石中; 斜长石约 $10 \%$ 15\%, 多为中长石, 发育卡斯巴-钠长石复合双晶和环带结 构; 暗色矿物以黑云母为主, 含量约 $8 \%$ 15\%, 多为 填隙状分布于长石、石英颗粒间，偶见角闪石.

\section{2 研究方法}

\section{1 锆石 $\mathrm{U}-\mathrm{Pb}$ 年代学}

用于 LA-ICP-MS 锆石 U-Pb 定年的靖居正长花 岗岩样品 SY56 采自靖居复式岩体东部板桥乡东坑村 WN 约 $1 \mathrm{~km}$ 通村公路边, 地理坐标为 $28^{\circ} 26^{\prime} 29.1^{\prime \prime} \mathrm{N}$ 和 $119^{\circ} 39^{\prime} 31.2^{\prime \prime}$. 挑选出新鲜样品用一般人工重砂 法分选锆石, 所选样品的锆石数量大于 1000 粒, 呈 淡棕褐色, 多为柱状, 长宽比多介于 2/1 4/1 之间, 直径多 $<0.15 \mathrm{~mm}$. 然后在双目镜下提纯置于环氧树 脂中制成标准的锆石分析靶，磨去表面的树胶，并将 锆石裸露磨去约 $1 / 3$ 强, 利用反射光与透射光反复检 验直至锆石充分暴露. 然后利用阴极发光图像分析 锆石内部结构, 阴极发光照片拍摄工作在中国地质 科学院矿产资源研究所 JEOLJXA-8900RL 型扫描电 镜上完成.

锆石 LA-ICP-MS U-Pb 年代学分析在中国地质 大学(武汉)地质过程与矿产资源国家重点实验室完 成, 使用的激光剥蚀系统为德国 Lamda Physik 公司 生产的 Geolas2005 深紫外(DUV)193nm UarF 准分子 激光剥蚀系统, 分析中采用的激光束斑直径为 $32 \mu \mathrm{m}$, 采用哈佛大学 91500 标准锆石作为外标校正, 使用的 LA-ICP-MS 为 Agilent7500a, 仪器测试条件及参数 见文献 [23]. 同位素比值数据采用 ICPMSDataCal(ver3.0)软件处理, 使用 Andersen ${ }^{[24]}$ 编制的软 件对处理结果进行普通铅校正, 并采用 ISPLOT3.23 ${ }^{[25]}$ 程序进行谐和年龄图绘制和加权平均年龄计算.

1) 浙江省第七地质大队, 靖居口幅 1:5 万区域地质调查报告, 2001. 15-21 

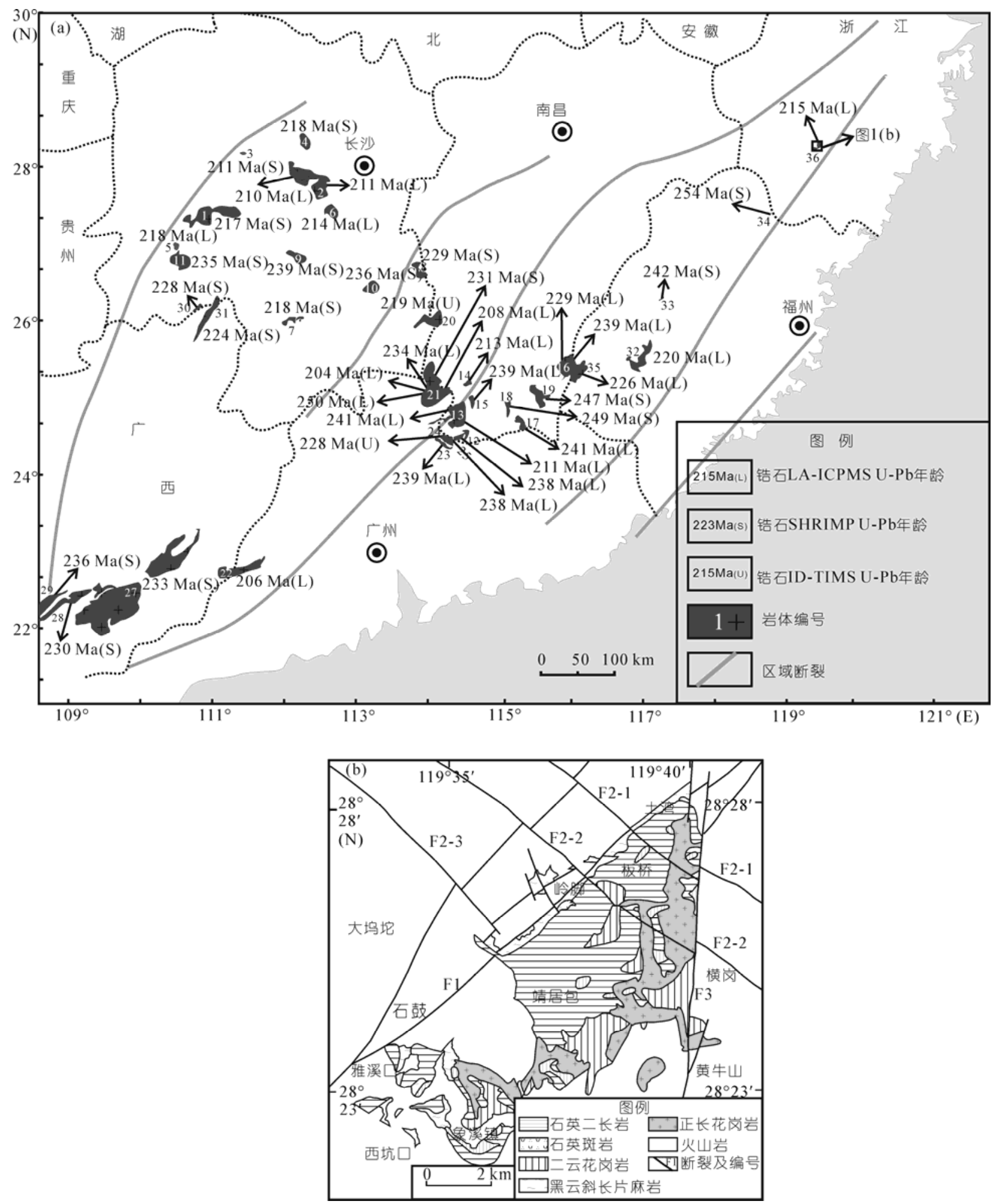

图 1 华南印支期岩浆岩时空分布图(a)和浙西南靖居复式岩体地质简图(b)

(a) 据文献[15]修改, 岩体年龄数据系根据文献资料补充; (b) 据脚注 1) 修改 


\section{2 全岩化学}

对靖居正长花岗岩分别进行了主量元素、微量元 素、Sr-Nd 同位素测试分析. 野外采集样品主要选择 在采石场和公路边, 以保证样品新鲜; 对于部分表面 风化的样品, 切除表面风化层选取内部新鲜部分. 将 挑选的新鲜样品完全粉碎至 $<200 \mu \mathrm{m}$, 为了尽量使样 品均匀, 具有代表性, 每个样品粉碎量约 $1 \mathrm{~kg}$. 将样 品粉末分为四份, 一份用于主量元素分析, 一份用于 微量及稀土元素分析, 一份用于 $\mathrm{Sr}-\mathrm{Nd}$ 同位素分析, 剩下留作备用.

主量元素测试在国土资源部武汉矿产资源监督 检测中心(武汉综合岩矿测试中心)完成, $\mathrm{H}_{2} \mathrm{O}$ 采用重 量法, $\mathrm{CO}_{2}$ 采用沸水滴定法分析, 其余氧化物由 $\mathrm{X}$ 荧 光光谱 $\alpha$ 系数测定, 分析精度为 $1 \%{ }^{[26]}$.

微量及稀土元素测试在中国地质大学(武汉)地 质过程与矿产资源国家重点实验室 Agilent 7500a ICP-MS 等离子体质谱仪上完成. 分析过程中 $\mathrm{HNO}_{3}$ 和 HF 试剂由优级纯酸经亚沸蒸馏装置制备的高纯试 剂, 水为 $18 \mathrm{M} \Omega . \mathrm{cm}$ 去离子水. 详细的样品消解处理 过程、分析精密度和准确度同 $\mathrm{Liu}$ 等 ${ }^{[27]}$.

\section{3 同位素分析}

$\mathrm{Sr}-\mathrm{Nd}$ 同位素测试分析工作在中国地质大学(武 汉)地质过程与矿产资源国家重点实验室 Finnigan Triton TIMS 上完成. 利用十万分之一的天平称取样 品 50 100 mg, 采用聚四氟乙烯的密封 bomb 溶解样 品, 加入 $\mathrm{HF}+\mathrm{HNO}_{3}$ 混合酸 $3 \mathrm{~mL}$ 使其充分溶解、蒸 干. 然后加入 $3 \mathrm{~mL} \mathrm{HF}+\mathrm{HNO}_{3}$ 混合酸, 密封后置 $190^{\circ} \mathrm{C}$ 烘箱中使样品完全溶解, 采用 AG50X8 阳离子
树脂柱和 HDEHP 进行 Sm-Nd 分离 ${ }^{[28]}$. 全过程本底为 $\mathrm{Sm}=6.5 \times 10^{-3} \mathrm{ppm}(1 \mathrm{ppm}=1 \mu \mathrm{g} / \mathrm{g}), \mathrm{Nd}=3.5 \times 10^{-3} \mathrm{ppm}$, 样品 ${ }^{143} \mathrm{Nd} /{ }^{144} \mathrm{Nd}$ 比值用 ${ }^{146} \mathrm{Nd} /{ }^{144} \mathrm{Nd}=0.721900$ 标准化, 标样 BCR-2 测定值为 ${ }^{143} \mathrm{Nd} /{ }^{144} \mathrm{Nd}=0.512643 \pm 0.000015$ $(2 \sigma),{ }^{147} \mathrm{Sm} /{ }^{144} \mathrm{Nd}=0.1365, \mathrm{Nd}=28.32 \mathrm{ppm}$, LaJolla: ${ }^{143} \mathrm{Nd} /{ }^{144} \mathrm{Nd}=0.511856 \pm 0.000012$.

\section{3 研究结果}

\section{1 锆石 U-Pb 年代学}

花岗岩中锆石的内部结构记录了岩石经历的复 杂地质演化历史. 吴元保和郑永飞 ${ }^{[29]}$ 认为, 岩浆锆石 一般具有特征的岩浆振荡环带, 高温条件下由于微 量元素扩散快常形成较宽的结晶环带，反之，低温形 成窄的环带. 另外, 岩浆锆石 $T h$ 和 $U$ 含量较高, Th/U 比值与 $\mathrm{Th}$ 和 $\mathrm{U}$ 在岩浆中的含量以及它们在锆石与岩 浆之间的分配系数有关，一般岩浆锆石 $\mathrm{Th} / \mathrm{U}>0.4$, 很 多接近 1. 靖居正长花岗岩 $\mathrm{Th} / \mathrm{U}$ 值介于 0.59 1.78 之 间, 多数>1(表 1), 在阴极发光图像(图 2)中显示出很 好的韵律振荡环带, 应属于典型的岩浆结晶的产物.

对靖居正长花岗岩(样品号 SY56)的 19 颗锆石进 行了 U-Pb 同位素定年, 分析结果列于表 1 . 这些数据 显示, 测点 SY56-4 的 ${ }^{206} \mathrm{~Pb} /{ }^{238} \mathrm{U}$ 为 $0.039, \mathrm{Th} / \mathrm{U}$ 比值 为 $1.56,{ }^{206} \mathrm{~Pb} /{ }^{238} \mathrm{U}$ 年龄为 $(244 \pm 5) \mathrm{Ma}$; 测点 $\mathrm{SY} Y 6-4$ 所在锆石的形态和结构与其他锆石均有一定差异, 为短板状，也不发育岩浆成因韵律环带(图 2), 且该

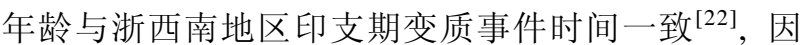
此有可能是岩浆上升过程中捕获的变质增生锆石. 测点 SY56-12 的 ${ }^{206} \mathrm{~Pb} /{ }^{238} \mathrm{U}$ 为 $0.036, \mathrm{Th} / \mathrm{U}$ 比值为 1.35 , ${ }^{206} \mathrm{~Pb} /{ }^{238} \mathrm{U}$ 年龄值为 $(230 \pm 4) \mathrm{Ma}$; 该测点所在锆石发

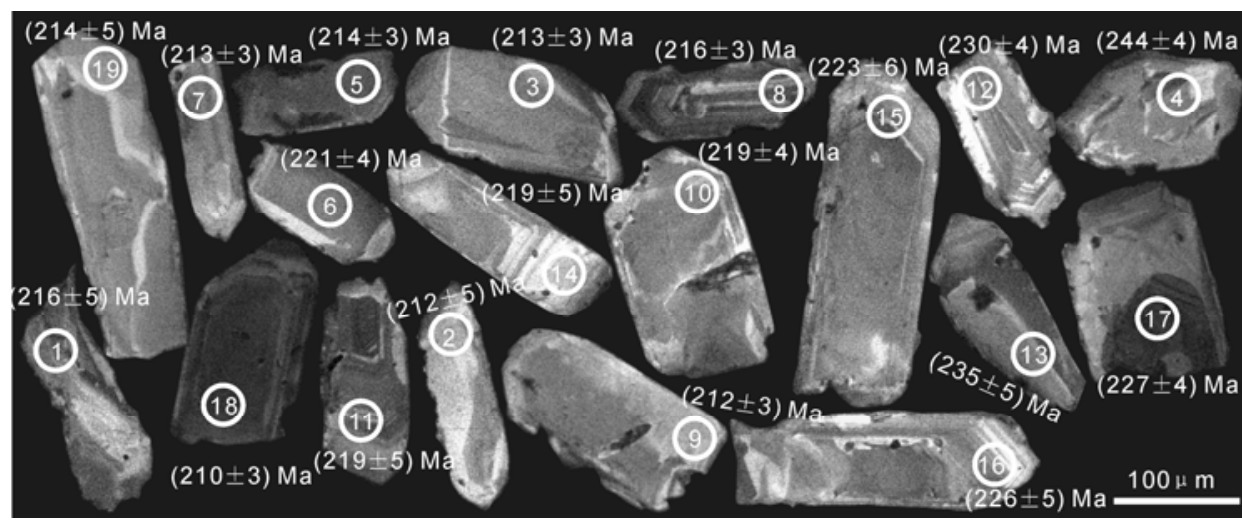

图 2 靖居正长花岗岩(SY56)锆石 CL 图像及微区 U-Pb 年龄分析点位 
表 1 靖居正长花岗岩 LA-ICP-MS 锆石 U-Th-Pb 同位素定年分析数据

\begin{tabular}{|c|c|c|c|c|c|c|c|c|c|c|}
\hline 测点号 & $\begin{array}{l}{ }^{232} \mathrm{Th} \\
\text { (ppm) }\end{array}$ & $\begin{array}{c}{ }^{238} \mathrm{U} \\
(\mathrm{ppm})\end{array}$ & $\begin{array}{c}\mathrm{Pb} \\
(\mathrm{ppm})\end{array}$ & ${ }^{32} \mathrm{Th} /{ }^{238} \mathrm{U}$ & ${ }^{207} \mathrm{~Pb} /{ }^{206} \mathrm{~Pb}$ & ${ }^{207} \mathrm{~Pb} /{ }^{235} \mathrm{U}$ & ${ }^{206} \mathrm{~Pb} /{ }^{238} \mathrm{U}$ & $\begin{array}{c}{ }^{207} \mathrm{~Pb} /{ }^{206} \mathrm{~Pb} \\
\text { 年龄 }(\mathrm{Ma})\end{array}$ & $\begin{array}{l}{ }^{207} \mathrm{~Pb} /{ }^{235} \mathrm{U} \\
\text { 年龄 }(\mathrm{Ma})\end{array}$ & $\begin{array}{l}{ }^{206} \mathrm{~Pb} /{ }^{238} \mathrm{U} \\
\text { 年龄 }(\mathrm{Ma})\end{array}$ \\
\hline SY56-1 & 174.1 & 151.4 & 6.8 & 1.15 & $0.05773 \pm 0.00319$ & $0.26561 \pm 0.01383$ & $0.03412 \pm 0.00081$ & $520 \pm 120$ & $239 \pm 11$ & $216 \pm 5$ \\
\hline SY56-2 & 105.8 & 102.7 & 4.5 & 1.03 & $5831 \pm 0.00453$ & $0.27290 \pm 0.02229$ & $0.03346 \pm 0.00088$ & $543 \pm 170$ & $245 \pm 18$ & $212 \pm 5$ \\
\hline SY56-3 & 163.5 & 116.9 & 5.4 & 1.40 & $0.05327 \pm 0.00301$ & $0.24928 \pm 0.01333$ & $0.03356 \pm 0.00054$ & $339 \pm 130$ & $226 \pm 11$ & $213 \pm 3$ \\
\hline SY56-4 & 284.0 & 181.5 & 10.3 & 1.56 & $0.05361 \pm 0.00234$ & $0.28463 \pm 0.01209$ & $0.03853 \pm 0.00086$ & $354 \pm 98$ & $254 \pm 10$ & $244 \pm 5$ \\
\hline SY56-5 & 399.9 & 512.8 & 21.1 & 0.78 & $0.05141 \pm 0.00164$ & $0.24405 \pm 0.00786$ & $0.03382 \pm 0.00056$ & $261 \pm 74$ & $222 \pm 6$ & $214 \pm 3$ \\
\hline SY56-6 & 572.1 & 402.6 & 19.6 & 1.42 & $0.05137 \pm 0.00207$ & $0.24985 \pm 0.00974$ & $0.03486 \pm 0.00065$ & $257 \pm 93$ & $226 \pm 8$ & $221 \pm 4$ \\
\hline SY56-7 & 458.2 & 263.2 & 13.4 & 1.74 & $0.05361 \pm 0.00219$ & $0.25063 \pm 0.01020$ & $0.03356 \pm 0.00053$ & $354 \pm 91$ & $227 \pm 8$ & $213 \pm 3$ \\
\hline SY56-8 & 463.5 & 259.8 & 13.6 & 1.78 & $0.05446 \pm 0.00192$ & $0.25875 \pm 0.00927$ & $0.03405 \pm 0.00050$ & $391 \pm 84$ & $234 \pm 7$ & $216 \pm 3$ \\
\hline SY56-9 & 221.4 & 282.1 & 11.7 & 0.78 & $0.05193 \pm 0.00207$ & $0.24316 \pm 0.01043$ & $0.03348 \pm 0.00050$ & $283 \pm 93$ & $221 \pm 9$ & $212 \pm 3$ \\
\hline SY56-10 & 218.7 & 179.2 & 8.3 & 1.22 & $0.05253 \pm 0.00282$ & $0.24675 \pm 0.01249$ & $0.03450 \pm 0.00068$ & $309 \pm 119$ & $224 \pm 10$ & $219 \pm 4$ \\
\hline SY56-11 & 309.0 & 309.6 & 13.4 & 1.00 & $0.05239 \pm 0.00296$ & $0.25117 \pm 0.01406$ & $0.03451 \pm 0.00078$ & $302 \pm 130$ & $228 \pm 11$ & $219 \pm 5$ \\
\hline SY56-12 & 550.7 & 407.7 & 20.8 & 1.35 & $0.05351 \pm 0.00164$ & $0.27040 \pm 0.00841$ & $0.03633 \pm 0.00065$ & $350 \pm 69$ & $243 \pm 7$ & $230 \pm 4$ \\
\hline SY56-13 & 205.9 & 241.6 & 11.4 & 0.85 & $0.05603 \pm 0.00220$ & $0.29178 \pm 0.01211$ & $0.03719 \pm 0.00079$ & $454 \pm 87$ & $260 \pm 10$ & $235 \pm 5$ \\
\hline SY56-14 & 100.4 & 130.5 & 5.2 & 0.77 & $0.05605 \pm 0.00424$ & $0.27359 \pm 0.02110$ & 0.034530 .00086 & $454 \pm 168$ & $228 \pm 11$ & $219 \pm 5$ \\
\hline SY56-15 & 266.6 & 319.0 & 13.5 & 0.84 & $0.04951 \pm 0.00211$ & $0.24430 \pm 0.00991$ & $0.03520 \pm 0.00089$ & $172 \pm 128$ & $222 \pm 8$ & $223 \pm 6$ \\
\hline SY56-16 & 278.5 & 381.4 & 16.4 & 0.73 & $0.05071 \pm 0.00205$ & $0.25397 \pm 0.00944$ & $0.03563 \pm 0.00087$ & $228 \pm 93$ & $230 \pm 8$ & $226 \pm 5$ \\
\hline SY56-17 & 389.4 & 661.4 & 26.9 & 0. & $0.04951 \pm 0.00152$ & $0.25352 \pm 0.00856$ & $0.03575 \pm 0.00079$ & $172 \pm 72$ & $229 \pm 7$ & $227 \pm 4$ \\
\hline SY56-18 & 334.9 & 325.0 & 13.8 & 1.03 & $0.04913 \pm 0.00171$ & $0.23072 \pm 0.00814$ & $0.03305 \pm 0.00054$ & $154 \pm 77$ & $211 \pm 7$ & $210 \pm 3$ \\
\hline SY56-19 & 94.7 & 76.4 & 3.5 & 1.24 & $0.06112 \pm 0.00458$ & $0.28881 \pm 0.01982$ & $0.03379 \pm 0.00072$ & $643 \pm 163$ & $258 \pm 16$ & $214 \pm 5$ \\
\hline
\end{tabular}

育核-边结构, 锆石边部被溶蚀呈港湾状, 测点位于 锆石内部. 测点 $\mathrm{SY} 56-13$ 的 ${ }^{206} \mathrm{~Pb} /{ }^{238} \mathrm{U}$ 为 $0.037, \mathrm{Th} / \mathrm{U}$ 比值为 $0.85,{ }^{206} \mathrm{~Pb} /{ }^{238} \mathrm{U}$ 为 $(235 \pm 5) \mathrm{Ma}$, 锆石形态极不 规则。这两个测点年龄与该岩体早期石英二长岩年 龄 $((233.7 \pm 1.8) \mathrm{Ma}$ ，未发表的资料)在误差范围内一 致, 可能是捕获早期石英二长岩的锆石. 测点 SY56-16 的 ${ }^{206} \mathrm{~Pb} /{ }^{238} \mathrm{U}$ 为 $0.036, \mathrm{Th} / \mathrm{U}$ 比值为 0.73 , ${ }^{206} \mathrm{~Pb} /{ }^{238} \mathrm{U}$ 年龄为 $(226 \pm 5) \mathrm{Ma}$; 在阴极发光图像上该 测点位于铅石核-边结合部位, 可能存在混合现象, 导致年龄值偏高. 测点 $\mathrm{SY} 56-17^{206} \mathrm{~Pb} /{ }^{238} \mathrm{U}$ 为 0.036 , $\mathrm{Th} / \mathrm{U}$ 比值为 $0.59,{ }^{206} \mathrm{~Pb} /{ }^{238} \mathrm{U}$ 年龄为 $(227 \pm 4) \mathrm{Ma}$; 在阴 极发光图像中, 测点 SY56-17 所在锆石具有明显的核边结构, 测点位于锆石核部. 这两个测点的年龄数据 非常谐和, 说明在该地区可能存在 $226 \mathrm{Ma}$ 的一次岩 浆事件. 其余锆石测点 ${ }^{206} \mathrm{~Pb} /{ }^{238} \mathrm{U}$ 值集中分布在 0.033 0.035 之间, 年龄集中在 210 223 Ma 之间.

在谐和图上(图 3(a)), 所有分析点都位于谐和线 上或下方附近, 在计算加权平均年龄时, 去除捕获锆 石的年龄, 仅保留 ${ }^{206} \mathrm{~Pb} /{ }^{238} \mathrm{U}$ 年齡集中在 $210 \sim 223$ $\mathrm{Ma}$ 之间 14 个数据, 占总测点的 $74 \%$, 具有很高的可 信度. 利用 ISPLOT3.23 程序计算得到 $(2145 \pm 2) \mathrm{Ma}$ 的 加权平均年龄(图 3(b)), 该年龄代表靖居正长花岗岩 的岩浆结晶年龄. 因此, 浙西南靖居正长花岗岩应为
印支期岩浆活动产物.

\section{2 地球化学特征}

靖居正长花岗岩主量元素和微量、稀土元素地球 化学测试结果列于表 2. 结果显示, 靖居正长花岗岩 $\mathrm{SiO}_{2}$ 含量除样品 $\mathrm{SY} 56$ 较低(为 $62.05 \%$ ) 外, 其余集中 在 $69.23 \%$ 71.49\%之间; 岩石富碱, $\mathrm{Na}_{2} \mathrm{O}+\mathrm{K}_{2} \mathrm{O}$ 含量 高达 9.09\% 12.36\%，明显高于已报道的其他华南印 支期 (240 204 Ma) 花岗岩的全碱含量; 在火成岩 $\mathrm{TAS}$ (硅-碱) 分类图解中, 靖居正长花岗岩落入正长 岩、石英二长岩及花岗岩范围内(图 4). 靖居正长花 岗岩富钾, $\mathrm{K}_{2} \mathrm{O}$ 含量 $(6.78 \%$ 7.94\%)远高于其他华南 印支期花岗岩 $\left(\mathrm{K}_{2} \mathrm{O}\right.$ 含量主体 $<6.42 \%$, 但赣南富城黑 云母花岗岩中一个样品的 $\mathrm{K}_{2} \mathrm{O}$ 含量高达 $7.55 \%{ }^{[45]}$ ). 在 $\mathrm{SiO}_{2}-\mathrm{K}_{2} \mathrm{O}$ 图上, 靖居正长花岗岩均落入钾玄岩系 列范围内(图 5), 岩石富铝, $\mathrm{Al}_{2} \mathrm{O}_{3}$ 含量介于 $13.20 \%$ $16.81 \%$ 之间, $\mathrm{A} / \mathrm{CNK}=0.88 \sim 1.10, \mathrm{~A} / \mathrm{NK}=1.06 \sim 1.27$, 在 A/CNK-A/NK 图解上(图 6), 落入准铝质 弱过铝 质区域. $\mathrm{K}_{2} \mathrm{O} 、 \mathrm{MgO}$ 及 $\mathrm{P}_{2} \mathrm{O}_{5}$ 含量与 $\mathrm{SiO}_{2}$ 含量具有明 显的负相关关系，而其他主要元素含量变化相关性 不明显(图略).

靖居正长花岗岩稀土元素总量( $\Sigma R E E)$ 较高, 介 于 933 1772 ppm 之间, 轻重稀土分馏明显, 轻稀土 

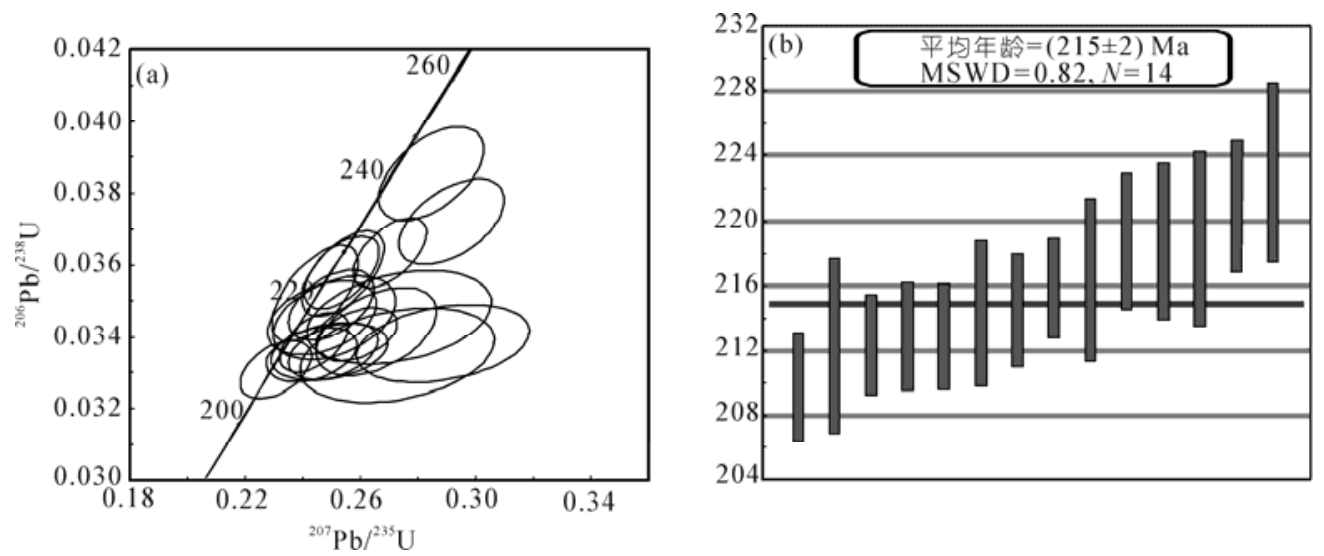

图 3 靖居正长花岗岩(SY56)锆石 U-Pb 谐和年龄(a)及加权平均年龄示意图(b)

(a)中数据点的椭圆代表了 $68.3 \%$ 的置信度; (b)中误差棒高度为 $1 \sigma$

表 2 靖居正长花岗岩主量 $(\%)$ 、微量元素(ppm)地球化学数据

\begin{tabular}{|c|c|c|c|c|c|c|c|c|c|}
\hline \multirow{2}{*}{$\begin{array}{l}\text { 岩性 } \\
\text { 样号 }\end{array}$} & \multicolumn{4}{|c|}{ 正长花岗岩 } & & \multicolumn{4}{|c|}{ 正长花岗岩 } \\
\hline & SY40-1 & SY51 & SY56 & SY60-1 & & SY40-1 & SY51 & SY56 & SY60-1 \\
\hline $\mathrm{SiO}_{2}$ & 69.79 & 69.23 & 62.05 & 71.49 & $\mathrm{Ga}$ & 24.3 & 27.7 & 30.2 & 25.0 \\
\hline $\mathrm{TiO}_{2}$ & 0.45 & 0.41 & 0.55 & 0.22 & $\mathrm{Rb}$ & 160 & 187 & 180 & 221 \\
\hline $\mathrm{Al}_{2} \mathrm{O}_{3}$ & 13.20 & 15.22 & 16.81 & 14.12 & $\mathrm{Ba}$ & 55.6 & 265 & 423 & 115 \\
\hline $\mathrm{FeO}$ & 2.87 & 1.45 & 3.60 & 1.77 & Th & 87.3 & 53.1 & 57.9 & 49.9 \\
\hline $\mathrm{Fe}_{2} \mathrm{O}_{3}$ & 1.80 & 1.45 & 1.40 & 0.47 & $\mathrm{U}$ & 2.47 & 1.61 & 2.09 & 4.75 \\
\hline $\mathrm{MnO}$ & 0.09 & 0.03 & 0.07 & 0.04 & $\mathrm{Nb}$ & 31.3 & 7.07 & 36.9 & 33.4 \\
\hline $\mathrm{MgO}$ & 0.12 & 0.18 & 0.28 & 0.09 & $\mathrm{Ta}$ & 1.13 & 0.44 & 1.51 & 2.15 \\
\hline $\mathrm{CaO}$ & 1.59 & 0.74 & 1.82 & 0.99 & $\mathrm{~Pb}$ & 24.8 & 36.3 & 31.8 & 35.2 \\
\hline $\mathrm{Na}_{2} \mathrm{O}$ & 2.23 & 2.76 & 4.42 & 2.83 & $\mathrm{Sr}$ & 69.5 & 171 & 177 & 54.3 \\
\hline $\mathrm{K}_{2} \mathrm{O}$ & 6.86 & 7.35 & 7.94 & 6.78 & $\mathrm{Zr}$ & 783. & 536 & 780 & 519 \\
\hline $\mathrm{P}_{2} \mathrm{O}_{5}$ & 0.03 & 0.04 & 0.08 & 0.02 & $\mathrm{Hf}$ & 19.0 & 13.0 & 18.5 & 14.1 \\
\hline $\mathrm{H}_{2} \mathrm{O}$ & 0.56 & 0.67 & 0.60 & 0.75 & $\mathrm{Y}$ & 38.4 & 18.4 & 51.0 & 39.9 \\
\hline $\mathrm{CO}_{2}$ & 0.29 & 0.31 & 0.20 & 0.29 & $\mathrm{La}$ & 465 & 488 & 316 & 250 \\
\hline$S$ & 0.01 & 0.01 & 0.01 & 0.01 & $\mathrm{Ce}$ & 818 & 827 & 569 & 429 \\
\hline \multirow[t]{2}{*}{ 总量 } & 99.89 & 99.85 & 99.83 & 99.87 & $\operatorname{Pr}$ & 95.9 & 89.5 & 68.2 & 47.9 \\
\hline & & & & & $\mathrm{Nd}$ & 308 & 268 & 230 & 154 \\
\hline $\mathrm{A} / \mathrm{CNK}$ & 0.94 & 1.10 & 0.88 & 1.02 & $\mathrm{Sm}$ & 38.2 & 25.5 & 30.3 & 19.9 \\
\hline $\mathrm{A} / \mathrm{NK}$ & 1.19 & 1.22 & 1.06 & 1.18 & $\mathrm{Eu}$ & 1.19 & 1.83 & 2.37 & 0.74 \\
\hline $\mathrm{FeO}^{*} / \mathrm{MgO}$ & 37.4 & 15.3 & 17.4 & 24.4 & $\mathrm{Gd}$ & 23.5 & 14.0 & 21.2 & 13.5 \\
\hline $\mathrm{Na}_{2} \mathrm{O}+\mathrm{K}_{2} \mathrm{O}$ & 9.09 & 10.11 & 12.36 & 9.61 & $\mathrm{~Tb}$ & 2.38 & 1.19 & 2.41 & 1.56 \\
\hline \multirow{2}{*}{$\left(\mathrm{Na}_{2} \mathrm{O}+\mathrm{K}_{2} \mathrm{O}\right) / \mathrm{CaO}$} & 5.72 & 13.66 & 6.79 & 9.71 & Dy & 9.91 & 4.17 & 11.7 & 7.59 \\
\hline & & & & & Ho & 1.62 & 0.69 & 2.04 & 1.41 \\
\hline$\delta \mathrm{Eu}$ & 0.11 & 0.27 & 0.27 & 0.13 & $\mathrm{Er}$ & 3.80 & 1.77 & 4.96 & 3.64 \\
\hline $10^{4} \mathrm{Ga} / \mathrm{Al}$ & 3.48 & 3.44 & 3.40 & 3.49 & $\mathrm{Tm}$ & 0.52 & 0.22 & 0.69 & 0.54 \\
\hline $\mathrm{Zr}+\mathrm{Nb}+\mathrm{Ce}+\mathrm{Y}$ & 1672 & 1389 & 1437 & 1021 & $\mathrm{Yb}$ & 3.49 & 1.37 & 4.14 & 3.57 \\
\hline $\mathrm{Zr}$ 饱和温度 $\left({ }^{\circ} \mathrm{C}\right)^{\mathrm{a})}$ & 930 & 904 & 895 & 895 & $\mathrm{Lu}$ & 0.59 & 0.20 & 0.63 & 0.52 \\
\hline
\end{tabular}

a) $\mathrm{Zr}$ 饱和温度计算据文献[30]

富集，重稀土亏损，在球粒陨石标准化稀土元素配分 曲线(图 7(a))上, 呈陡的右倾型, LREE/HREE 变化在
25.5 37.7 之间, $\mathrm{La}_{\mathrm{N}} / \mathrm{Yb}_{\mathrm{N}}$ 分布在 50.2 95.4 之间, 其 $\delta \mathrm{Eu}$ 介于 $0.12 \sim 0.29$ 之间, 表现出显著的负铀异常. 在 


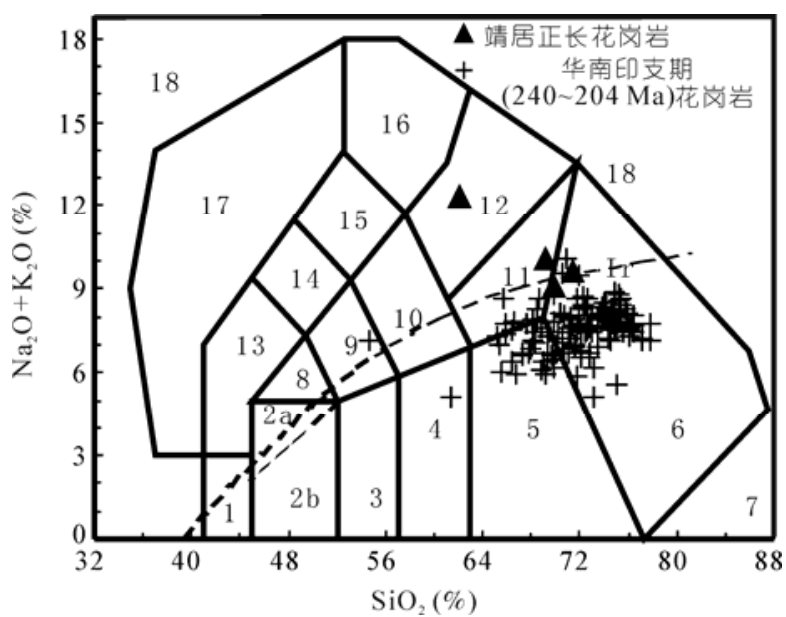

图 4 TAS 分类图

底图据文献[31]; 虚线上方为碱性系列, 下方为亚碱性系列; 华南 (240 204 Ma)花岗岩数据来自文献 $[11,13,32$ 46]. 1. 檄榄辉长岩; 2a. 碱性辉长岩; 2 b. 亚碱性辉长岩; 3 . 辉长闪长岩; 4 . 闪长岩; 5 . 花岗闪长岩; 6. 花岗岩; 7. 硅英岩; 8. 二长辉长岩; 9. 二长闪长岩; 10. 二长岩; 11. 石英二长岩; 12. 正长岩; 13. 副长石辉长岩; 14. 副长石二长闪长岩; 15. 副长石二长正长岩; 16. 副长石正长岩; 17. 副长石深成岩; 18 . 霓方钠岩/磷霞岩/粗白榴岩

岩石微量元素(岩石/原始地幔标准化)蛛网图上(图 7(b)), 靖居正长花岗岩强烈亏损 $\mathrm{Nb}, \mathrm{Ta}, \mathrm{Ti}, \mathrm{P}$ 等高场 强元素和 $\mathrm{Ba}, \mathrm{Sr}$ 等大离子亲石元素.

\subsection{Sr-Nd 同位素}

从以上主、微量元素分析的样品中挑选出 SY51, SY56, SY60-1 三件进行 Sr-Nd 同位素测试分析, 测试 数据列于表 3. 岩石 ${ }^{87} \mathrm{Rb} /{ }^{86} \mathrm{Sr}$ 变化于 $2.943 \sim 3.170$, 范

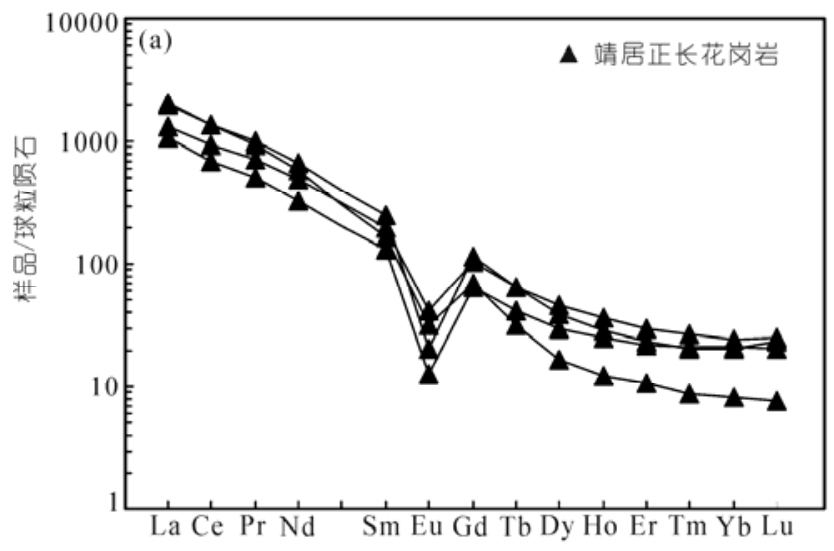

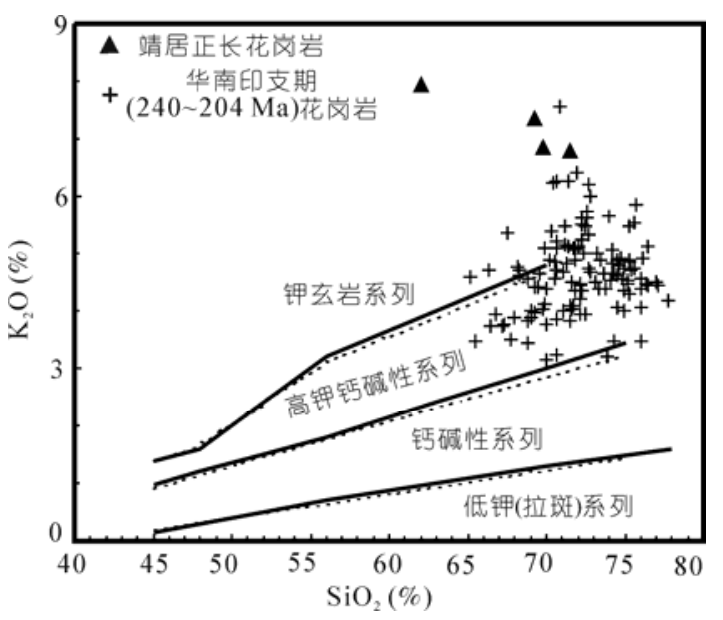

图 $5 \mathrm{SiO}_{2}-\mathrm{K}_{2} \mathrm{O}$ 图解

底图据文献[47], 华南花岗岩数据来源同图 4

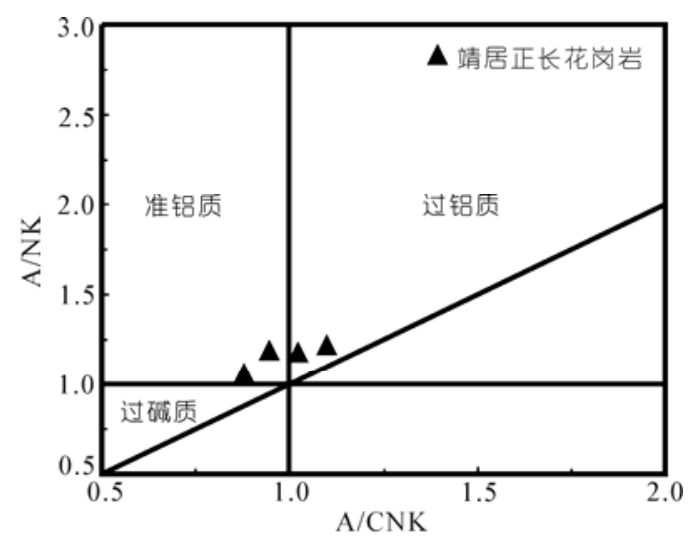

图 $6 \mathrm{~A} / \mathrm{CNK}-\mathrm{A} / \mathrm{NK}$ 图解

底图据文献[48]; $\mathrm{A}-\mathrm{Al}_{2} \mathrm{O}_{3} ; \mathrm{C}-\mathrm{CaO} ; \mathrm{N}-\mathrm{Na}_{2} \mathrm{O} ; \mathrm{K}-\mathrm{K}_{2} \mathrm{O}$. 单位: $\mathrm{mol} \%$

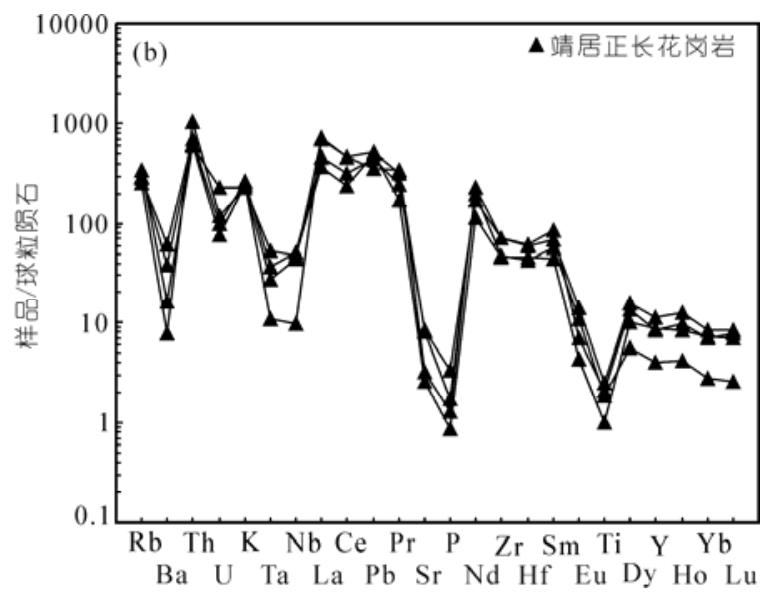

图 7 靖居正长花岗岩稀土元素球粒陨石标准化配分曲线(a)及微量元素原始地幔标准化蛛网图(b) 原始地幔标准化数据、球粒陨石标准化数据据文献[49] 
围较小. ${ }^{87} \mathrm{Sr} /{ }^{86} \mathrm{Sr}$ 比值分布于 $0.728 \sim 0.729$ 之间. 岩石 ${ }^{147} \mathrm{Sm} /{ }^{144} \mathrm{Nd}$ 比值较低, 变化在 $0.058 \sim 0.080$ 之间; ${ }^{143} \mathrm{Nd} /{ }^{144} \mathrm{Nd}$ 分布于 $0.5117 \sim 0.5118$ 之间.

沈渭洲等 ${ }^{[20,50,51]}$ 研究认为, 华夏地块中生代火成 岩具有较低的 $\varepsilon_{\mathrm{Nd}}(t)$ 值, 较高的 $I_{\mathrm{Sr}}$ 值和较为古老的 $\mathrm{Nd}$ 模式年龄. 浙江境内中生代火成岩主要由基底变质 沉积岩衍生, 原始岩浆的形成受制于中、下地壳物质 的部分熔融 ${ }^{[52]}$. 前人研究认为浙江中生代火成岩 $I_{\mathrm{Sr}}$ 值介于 $0.707 \sim 0.710$ 之间, $\varepsilon_{\mathrm{Nd}}(t)$ 值介于-10.0 -6.0 之 间 ${ }^{[52,53]}$.

分属扬子地块和华夏地块的浙江中生代火成岩 在 Sr-Nd 同位素组成上存在明显差异, 但是在同一地 块内部火山岩与侵入岩具有相似的同位素组成. 在 扬子地块内, 火山岩与侵入岩 $I_{\mathrm{Sr}}$ 值和对应的 $\varepsilon_{\mathrm{Nd}}(t)$ 值 变化均较小; 而在华夏地块内, $I_{\mathrm{Sr}}$ 值及对应的 $\varepsilon_{\mathrm{Nd}}(t)$ 值 变化较大. 尤其在次级构造带内部, 火山岩与侵入岩 在同位素上的相似性表现得更为显著 ${ }^{[52]}$.

利用本文所得的靖居正长花岗岩 LA-ICP-MS 锆 石 U-Pb 年龄 $(215 \mathrm{Ma}$ )进行拟合计算, 获得 0.7179 , $0.7203,0.7199$ 的 $I_{\mathrm{Sr}}$ 值和分别为 $-14.2,-13.9,-13.2$ 的 $\varepsilon_{\mathrm{Nd}}(t)$ 值 (表 3 ), 相应的两阶段 $\mathrm{Nd}$ 模式年龄为 $2.07 \sim 2.14 \mathrm{Ga}$. 从以上数据可知: 靖居正长花岗岩具 有比浙江其他中生代(主要为晚中生代)火成岩相对 较高的 $I_{\mathrm{Sr}}$ 值和较低的 $\varepsilon_{\mathrm{Nd}}(t)$ 值.

\section{4 岩石成因与构造环境}

\section{1 岩石类型及其成因}

花岗岩的分类及其成因一直是广大地质学者关 注的焦点. 花岗岩通常被分为 I 型、 $S$ 型、 $M$ 型和 $A$ 型, 前三种类型主要是根据其源岩性质划分, $\mathrm{A}$ 型花 岗岩则是由 Loiselle 和 Wones ${ }^{[54]}$ 提出的一类具特殊地
球化学特征及特定构造背景的花岗岩. 但是 A 型花 岗岩与高分异 I 型花岗岩依然很难区分, 与 I 型花岗 岩相比, $\mathrm{A}$ 型花岗岩具有相对较高的 $\mathrm{K}_{2} \mathrm{O}$ 含量、HFSE 含量及 $\mathrm{FeO} / \mathrm{MgO}$ 比值、 $10^{4} \mathrm{Ga} / \mathrm{Al}$ 值等.

如前所述, 靖居正长花岗岩具有较高的 $\mathrm{K}_{2} \mathrm{O}$ 含 量、稀土元素含量和 HFSE 含量特征. 在 Whalen 等 ${ }^{[55]}$ 的 A 型花岗岩判别图解包括 $\mathrm{FeO} / \mathrm{MgO}-10^{4} \mathrm{Ga} / \mathrm{Al}$, $\left(\mathrm{K}_{2} \mathrm{O}+\mathrm{Na}_{2} \mathrm{O}\right) / \mathrm{CaO}-10^{4} \mathrm{Ga} / \mathrm{Al}, \quad \mathrm{FeO} / \mathrm{MgO}-(\mathrm{Zr}+\mathrm{Nb}+\mathrm{Ce}+$ $\mathrm{Y}),\left(\mathrm{K}_{2} \mathrm{O}+\mathrm{Na}_{2} \mathrm{O}\right) / \mathrm{CaO}-(\mathrm{Zr}+\mathrm{Nb}+\mathrm{Ce}+\mathrm{Y})$ 中, 靖居正长花 岗岩所有样品均落入 $\mathrm{A}$ 型花岗岩范围内(图 8).

锆石是花岗岩中结晶较早的矿物, 锆石中锆的 分配系数受温度控制较为明显, 其锆石饱和温度可 近似为岩浆结晶温度. 根据 Watson 和 Harrison ${ }^{[30]}$ 的 公式, 用岩石主要元素及其 $\mathrm{Zr}$ 含量计算得到靖居正 长花岗岩锆石饱和温度在 $895 \sim 930^{\circ} \mathrm{C}$ 之间, 与 $\mathrm{A}$ 型花 岗岩形成于高温条件这一特征吻合. 另外, 黑云母在 显微镜下多为他形的绿色富铁黑云母, 这也与全岩 $\mathrm{FeO} / \mathrm{MgO}(15 \sim 37)$ 高的特征相一致; 此外, 岩石中还 有自形石英产出. 所有这些, 都符合 $\mathrm{A}$ 型花岗岩的特 征. 因此, 靖居正长花岗岩应为铝质 $\mathrm{A}$ 型花岗岩.

前人的研究表明, 华南印支期花岗岩多为古变 质沉积岩部分熔融的产物 ${ }^{[10,11,36,37,56]}$, 它们大多被认 为是过铝质 I 型或 $S$ 型花岗岩. 而本文的资料表明, 靖居正长花岗岩应属于印支期铝质 $\mathrm{A}$ 型花岗岩. 前 人对 $\mathrm{A}$ 型花岗岩的成因提出了多种模式, 主要有幔 源玄武质岩浆的结晶分异作用, 幔源岩浆与壳源岩 浆的混合作用，地壳物质的部分熔融等.

目前，除湖南道县有印支期基性岩的年龄报道 外, 包括浙西南地区在内的中国东南地区均未发现 印支期基性岩浆活动产物，而靖居复式岩体中相对 基性的石英二长岩的矿物成分及一些地球化学参数 与正长花岗岩之间存在很大的差异, 二者的化学成

表 3 靖居正长花岗岩 Sr-Nd 同位素测试结果 ${ }^{\text {a) }}$

\begin{tabular}{|c|c|c|c|c|c|c|c|c|c|c|c|c|}
\hline 样品号 & $\begin{array}{c}\mathrm{Rb} \\
(\mathrm{ppm})\end{array}$ & $\begin{array}{c}\mathrm{Sr} \\
(\mathrm{ppm})\end{array}$ & ${ }^{87} \mathrm{Rb} /{ }^{86} \mathrm{Sr}$ & ${ }^{87} \mathrm{Sr} /{ }^{86} \mathrm{Sr}$ & $I_{\mathrm{Sr}}$ & $\begin{array}{c}\mathrm{Sm} \\
(\mathrm{ppm})\end{array}$ & $\begin{array}{c}\mathrm{Nd} \\
(\mathrm{ppm})\end{array}$ & $\begin{array}{l}{ }^{147} \mathrm{Sm} / \\
{ }^{144} \mathrm{Nd}\end{array}$ & $\begin{array}{l}{ }^{143} \mathrm{Nd} / \\
{ }^{144} \mathrm{Nd}\end{array}$ & $\varepsilon_{\mathrm{Nd}}(t)$ & $\begin{array}{l}T_{\mathrm{DM}} \\
(\mathrm{Ga}) \\
\end{array}$ & $\begin{array}{l}T_{2 \mathrm{DM}} \\
(\mathrm{Ga})\end{array}$ \\
\hline SY51 & 187 & 171 & 3.169969 & 0.727558 & 0.7179 & 25.5 & 268 & 0.057486 & 0.511717 & -14.2 & 1.40 & 2.14 \\
\hline SY56 & 180 & 177 & 2.943350 & 0.729323 & 0.7203 & 30.3 & 230 & 0.079536 & 0.511761 & -13.9 & 1.57 & 2.12 \\
\hline SY60-1 & 221 & 54.3 & 3.012876 & 0.728045 & 0.7199 & 19.9 & 154 & 0.078330 & 0.511795 & -13.2 & 1.52 & 2.07 \\
\hline
\end{tabular}

a) $\varepsilon_{\mathrm{Nd}}(t)=\left[\left({ }^{143} \mathrm{Nd} /{ }^{144} \mathrm{Nd}\right)_{\mathrm{S}}(t) /\left({ }^{143} \mathrm{Nd} /{ }^{144} \mathrm{Nd}\right)_{\mathrm{CHUR}}(t)-1\right] \times 10000 ;\left({ }^{143} \mathrm{Nd} /{ }^{144} \mathrm{Nd}\right)_{\mathrm{CHUR}}(t)=\left({ }^{143} \mathrm{Nd} /{ }^{144} \mathrm{Nd}\right)_{\mathrm{CHUR}}-\left({ }^{147} \mathrm{Sm} /{ }^{144} \mathrm{Nd}\right)_{\mathrm{CHUR}}\left(\mathrm{e}^{\lambda t}-1\right), T_{2 \mathrm{DM}}=1 / \lambda \times \ln \{1+$ $\left.\left\{\left({ }^{143} \mathrm{Nd} /{ }^{144} \mathrm{Nd}\right)_{\mathrm{S}}-\left({ }^{143} \mathrm{Nd} /{ }^{144} \mathrm{Nd}\right)_{\mathrm{DM}}-\left[\left({ }^{147} \mathrm{Sm} /{ }^{144} \mathrm{Nd}\right)_{\mathrm{S}}-\left({ }^{147} \mathrm{Sm} /{ }^{144} \mathrm{Nd}\right)_{\mathrm{C}}\right]\left(\mathrm{e}^{\lambda t}-1\right)\right\} /\left[\left({ }^{147} \mathrm{Sm} /{ }^{144} \mathrm{Nd}\right)_{\mathrm{C}}-\left({ }^{147} \mathrm{Sm} /{ }^{144} \mathrm{Nd}\right)_{\mathrm{DM}}\right]\right\}, \lambda=6.54 \times 10^{-12} \mathrm{a}^{-1}, \quad \varepsilon_{\mathrm{Nd}}(t)$ 值计算采用 $\left({ }^{143} \mathrm{Nd} /{ }^{144} \mathrm{Nd}\right)_{\mathrm{CHUR}}=0.512638$. 式中: 下标 $\mathrm{DM}, \mathrm{S}$ 和 $\mathrm{C}$ 分别代表亏损地幔值、现今测试值、大陆地壳平均值; $\left({ }^{147} \mathrm{Sm} /{ }^{144} \mathrm{Nd}\right)_{\mathrm{DM}}=0.2136$, $\left({ }^{143} \mathrm{Nd} /{ }^{144} \mathrm{Nd}\right)_{\mathrm{DM}}=0.513151 ;\left({ }^{147} \mathrm{Sm} /{ }^{144} \mathrm{Nd}\right)_{\mathrm{c}}=0.118 ; t$ 代表样品结晶年龄, 为 $215 \mathrm{Ma}$ 

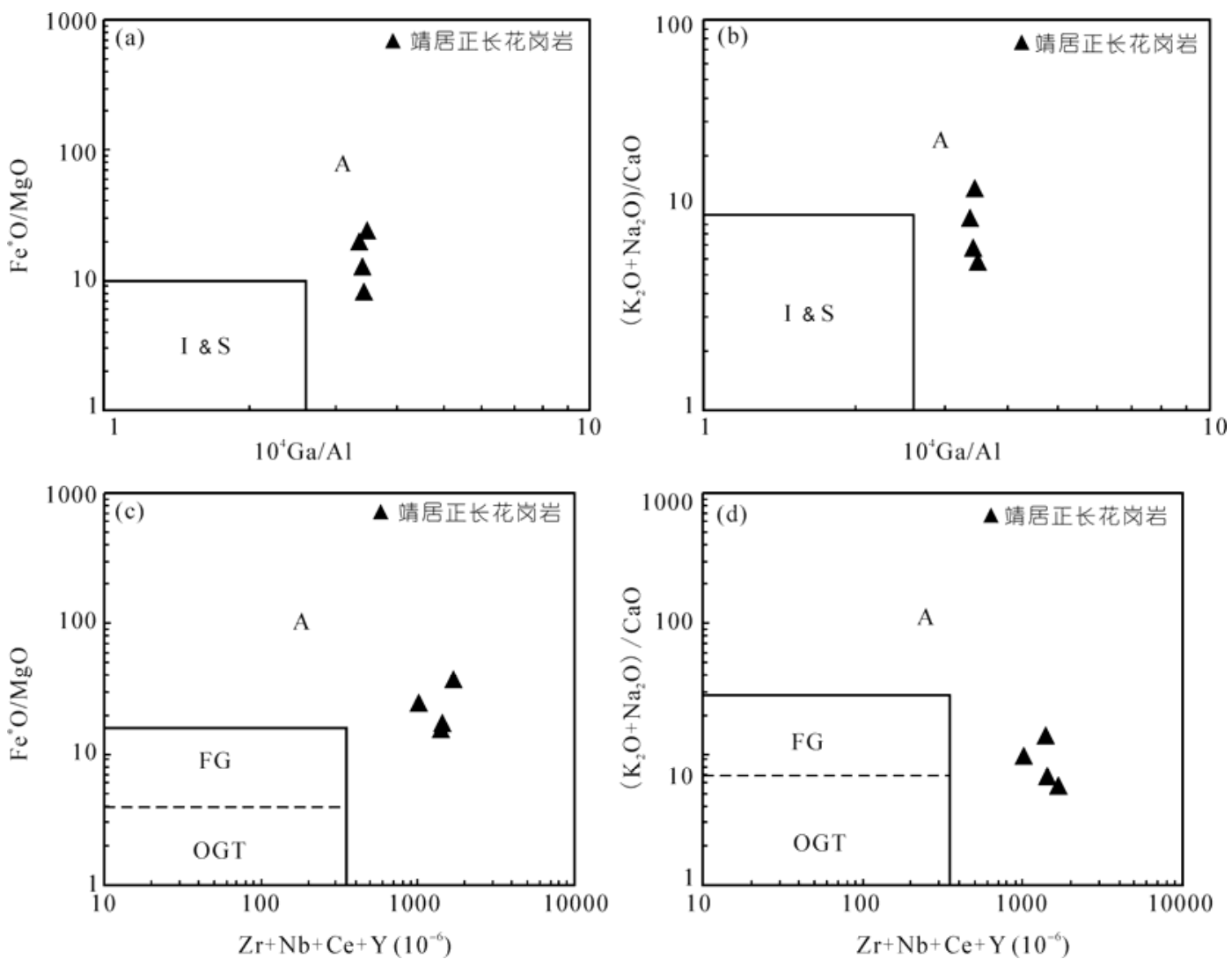

图 8 靖居正长花岗岩 $\mathbf{A}$ 型花岗岩判别图解

底图据文献[55]

分也不具明显的演化趋势 ${ }^{1)}$, 这表明正长花岗岩不可 能是石英二长岩的结晶分异产物. 此外, 靖居正长花 岗岩具有较高的 $I_{\mathrm{Sr}}$ 值和较低的 $\varepsilon_{\mathrm{Nd}}(t)$ 值, 这些同位素 组成特征也不同于幔源岩浆的演化产物.

岩浆混合作用也很难解释靖居正长花岗岩的成 因. 首先, 野外并未在正长花岗岩中发现与岩浆混合 作用有关的暗色微粒包体; 而且, 在 $\varepsilon_{\mathrm{Nd}}(t)$ 及大部分 元素与 $\mathrm{SiO}_{2}$ 图解(图略)上也不存在二端元混合作用 的线性趋势.

靖居正长花岗岩具有明显的 $\mathrm{Sr}$ 及 $\mathrm{Eu}$ 的负异常, 如果结晶分异作用不明显, 其中的 $\mathrm{Sr}$ 及 $\mathrm{Eu}$ 的负异常 就应该是源区稳定存在斜长石的标志. $\mathrm{Nb}$ 的亏损表 明岩石熔融的源岩可能以陆壳物质为主 ${ }^{[38,57 \sim 59]}$ 或受 到了俯冲组分的影响. 此外, 靖居正长花岗岩的两阶 段 $\mathrm{Nd}$ 模式年龄 $T_{2 \mathrm{DM}}(2.07 \sim 2.14 \mathrm{Ga})$ 为古元古代, 在 $\varepsilon_{\mathrm{Nd}}(t)-t$ 图解上, 其落入华夏古元古代基底演化域中 (图 9). 因此, 华夏地块古老基底岩石的部分熔融可 以很好的解释靖居正长花岗岩的岩浆物质来源.

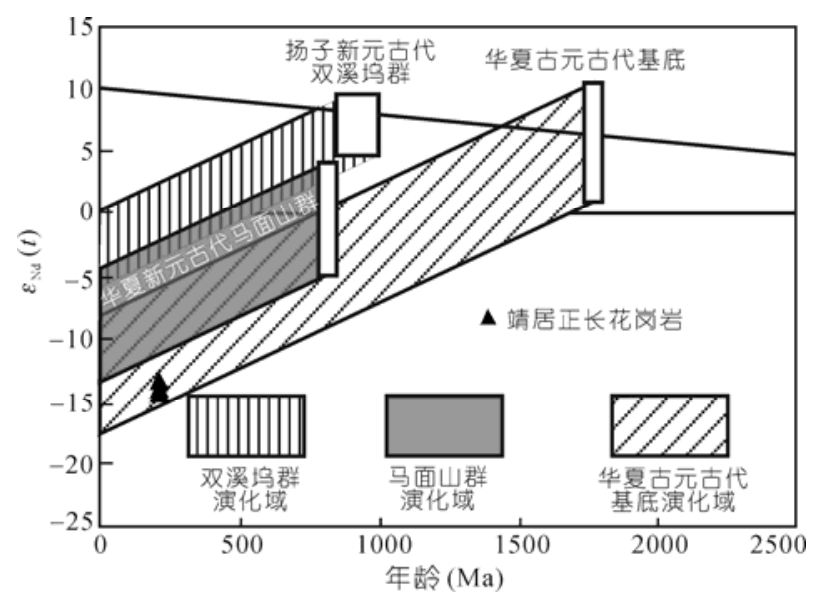

图 9 靖居正长花岗岩 $\varepsilon_{\mathrm{Nd}}(t)-t$ 图解 据文献[60 66]

\section{2 年代学意义}

陈多福等 ${ }^{[67]}$ 对浙江景宁地区鹤溪群斜长角闪岩 的变质新生锆石的 SHRIMP U-Pb 定年结果为 $(252 \pm 5)$ 
$\mathrm{Ma}$, 向华等 ${ }^{[21,22]}$ 对浙江淡竹黑云斜长角闪岩、斜长角 闪岩及景宁角闪岩的变质铅石的 SHRIMP U-Pb 定年 结果分别为 $(240 \pm 2.8),(233.8 \pm 2.8),(251.1 \pm 1.9) \mathrm{Ma}$, 上述年龄的报道均表明浙江地区经历了较为强烈的 印支期变质作用. 然而, 到目前为止, 在浙江地区可 靠的印支期岩浆事件的报道不多. 孙涛 ${ }^{[15]}$ 最新的统 计将浙江金罗后、庙后及山后岩体归为印支期花岗岩， 但前人资料及我们最新的定年资料均表明，这三个 岩体主体均为元古代岩浆活动产物(项目组未发表资 料).

前人曾利用 K-Ar 法对浙西南靖居复式岩体开展 了年代学研究, 获得石英二长岩黑云母 $\mathrm{K}-\mathrm{Ar}$ 年龄为 117.6 Ma, 而细粒二云母花岗岩的全岩 $\mathrm{K}-\mathrm{Ar}$ 年龄为 $106 \mathrm{Ma}$, 且根据侵入关系, 中粗粒正长花岗岩均晚于 前两者, 故将其定为白严纪岩浆活动产物 ${ }^{1}$. 本文就 该岩体开展的高精度 LA-ICP-MS 锆石 U-Pb 定年结 果显示, 靖居正长花岗岩的结晶年龄为 $(215 \pm 2) \mathrm{Ma}$, 为印支期岩浆活动的产物. 靖居正长花岗岩高精度 印支期年龄的获得, 肯定了浙江早中生代岩浆活动 的存在，为理解该区构造演化提供了新资料.

前人总结了华南印支期岩浆活动的时空分布,

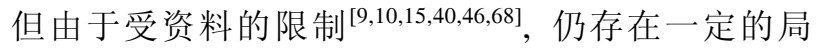
限性. 周新民 ${ }^{[10]}$ 的统计表明, 华南印支期岩浆事件多 为 $\mathrm{T}_{3}$ 时期, 介于 230 205 Ma 之间; 李献华和李武 显 ${ }^{[68]}$ 则认为华南内陆三叠纪花岗岩的形成时代主要 集中在 230 250 Ma; 王岳军等 ${ }^{[40]}$ 也认为华南内陆传 统上被认为属印支早期或海西-印支期的过铝质花岗 岩有着非常局限的时代(230 244 Ma); 陈卫峰等 ${ }^{[37,38]}$ 则认为广西、广东、海南及福建的岩浆活动以印支早 期为主，湖南则以印支晚期为主.

近年来文献中陆续有华南印支期岩浆事件的报 道, 表明华南印支期岩浆活动的影响范围远超过了 前人的预期. 本文综合了近年来发表的华南地区印 支期岩浆活动的高精度锆石 U-Pb 年龄资料(图 1(a), 10), 结果表明其形成时代介于 204 254 Ma 之间, 整 体上 $\mathrm{T}_{3}$ 时期岩浆岩主要分布在西北部的湖南及湘赣 粤交界地带, 而东南部的则以 $\mathrm{T}_{1}$ 和 $\mathrm{T}_{2}$ 为主.

\section{3 构造背景}

对华南印支期花岗岩形成背景的认识还存在很 大的分歧. 孙涛等 ${ }^{[11]}$ 认为, 华南印支期花岗岩(介于 240 205 Ma 之间)晚于印支运动的变质峰期(258 243

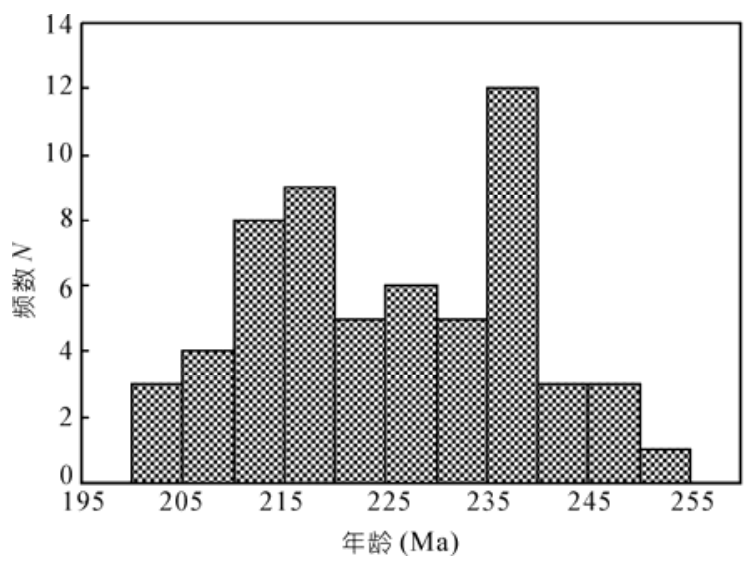

图 10 华南印支期花岗岩年龄柱状图

数据来源于 $[5,9,11 \sim 13,36 \sim 38,40 \sim 46,69 \sim 80]$

Ma), 属于后碰撞花岗岩, 是由加厚地壳在伸展体制 下部分熔融产生的. Zhou 等 ${ }^{[2]}$ 认为, 印支早期花岗岩 (251 234 Ma)为挤压环境下的同碰撞花岗岩, 而印支 晚期花岗岩(234 205 Ma)则是局部伸展环境下的后 碰撞花岗岩. Wang 等 ${ }^{[46]}$ 认为, 印支早期花岗岩 (243 228 Ma) 为挤压环境下的同碰撞花岗岩, 而印支 晚期(220 206 Ma)则转变为伸展环境下的后碰撞花 岗岩. 于津海等 ${ }^{[18]}$ 则认为, 华南的印支期变质-岩浆 活动具有两阶段特征，第一阶段花岗岩(249 225 Ma) 形成于同碰撞环境, 第二阶段花岗岩(225 207 Ma)为 后碰撞或碰撞晚期的产物.

上述研究得到的共同结论是: 华南印支期花岗岩, 早期形成于挤压环境，晚期形成于伸展环境. 但对于 由挤压向伸展环境转换的时间问题, 依然存在争议.

值得注意的是，华南印支期花岗岩 90\%以上为 过铝质 I 型或 $S$ 型花岗岩，其中强过铝花岗岩占印支 期花岗岩的 $72.7 \%^{[15]}$. 另外, 年代学资料表明, 华南 地区的一些复式岩体, 岩浆活动延续时间长, 可能一 个岩体内印支早期、印支晚期甚至燕山期的花岗岩都 有产出，如江西的龙源坝岩体 ${ }^{[74]}$ 及粤赣交界的诸广 山岩体 ${ }^{[77]}$. 但这些岩体中印支早期和印支晚期花岗 岩在元素地球化学特征方面差别不大 ${ }^{[35,77]}$. 因此, 必 须结合多方面的地质资料, 才能合理解释花岗岩形 成的构造环境.

邵建国等 ${ }^{[81,82]}$ 对云开地区碰撞挤压作用形成的 三个糜棱岩化花岗岩的新生白云母的 $\mathrm{Ar}-\mathrm{Ar}$ 定年结 果分别为 $(255.3 \pm 3.0),(249.7 \pm 2.6)$ 及 $(229.4 \pm 2.5) \mathrm{Ma}$; 彭少梅等 ${ }^{[83}$ 对云开分界地区逆冲断层的新生白云母 
的 $\mathrm{Ar}-\mathrm{Ar}$ 定年结果为 $235 \sim 247 \mathrm{Ma}$. 陈多福等 ${ }^{[67]}$ 及向 华等 ${ }^{[22]}$ 对浙江遂昌及景宁地区的变质锆石的 U-Pb 定 年结果为 234 252 Ma. 上述年代学结果均表明, 华 南印支早期(>229 Ma)为挤压环境.

梁新权等 ${ }^{[8,85]}$ 通过对十万大山盆地的构造及沉 积学研究认为, 扬子地块和华夏地块在印支早期发 生了强烈的陆内碰撞与汇聚及前陆盆地的沉积作用, 中、晚三叠世由挤压构造向伸展构造转换, 这标志着 自晚二叠世开始的碰撞造山作用的结束. 华南内部 晚二叠世-中三叠世构造运动性质及转换受古特提斯 洋的闭合及印支板块与华南陆块的碰撞作用影响. Wang 等 ${ }^{86,87]}$ 在对雪峰山构造带和十万大山构造带的 研究中, 获得了与伸展构造有关的年龄分别为 195 217 和 208 218 Ma, 在误差范围内与靖居正长花岗岩 的形成时代((215 \pm 2$) \mathrm{Ma})$ 基本一致.

本文报道的靖居正长花岗岩具有 $\mathrm{A}$ 型花岗岩的 岩石学、矿物学、地球化学特征, 有理由认为靖居正 长花岗岩为 $\mathrm{A}$ 型花岗岩. $\mathrm{A}$ 型花岗岩形成于伸展的构 造背景这一结论已得到大多数学者的认可. 因此, 靖 居岩体中的 $\mathrm{A}$ 型正长花岗岩的产出, 意味着至少在 $215 \mathrm{Ma}$ 时浙西南地区就处于伸展的构造背景下.

前人多将华南印支期岩浆活动归因于与印支地 块和华南陆块碰撞相关的印支运动的影响, 然而, $\mathrm{Li}$ 等 ${ }^{[6]}$ 在海南岛发现了代表古太平洋板块俯冲产生的 二叠纪弧岩浆活动, 并认为华南印支期岩浆活动受 控于古太平洋板块俯冲的影响; Wang 等 $^{[5]}$ 的研究也 表明, 古太平洋板块在印支期已影响到东南沿海地
区. 本文厘定的靖居 $\mathrm{A}$ 型花岗岩与Wang 等 ${ }^{[5]}$ 厘定的 铁山及洋坊碱性岩等指示伸展性质的岩体一起构成 一条近垂直于古太平洋板块俯冲方向的岩浆岩带, 然而在其西部的江西、湖南地区至今未有此类岩石的 报道, 也表明这些岩浆岩并非主要受印支地块与华 南陆块的后碰撞过程所控制, 而更可能是古太平洋 板块俯冲影响下的产物.

\section{5 结论}

(1) LA-ICP-MS 年代学结果显示, 浙西南的靖居 正长花岗岩侵位年龄为 $(215 \pm 2) \mathrm{Ma}$. 该年龄的获得填 补了中国东南沿海印支期岩浆活动的空白, 说明华 南印支期花岗岩并非以往研究所认为的仅在西南部 呈面状分布, 在东南沿海也有产出.

(2) 岩石学、矿物学、地球化学特征显示, 靖居 正长花岗岩为 $\mathrm{A}$ 型花岗岩. 结合前人对云开、雪峰等 地研究成果, 说明华南地区至少在印支期 $(215 \mathrm{Ma}$ ) 就 处于伸展的构造背景下, 其可能受控于古太平洋板 块的俯冲作用, 这表明古太平洋板块俯冲作用对华 南的影响可能在三叠纪就已存在.

(3) Sr-Nd 同位素研究显示, 靖居正长花岗岩比 该区晚中生代火成岩具有相对较低的 $\varepsilon_{\mathrm{Nd}}(t)$ 值、较高 $\mathrm{I}_{\mathrm{Sr}}$ 值和较古老的 $T_{2 \mathrm{DM}}$, 这与华夏地块古老的基底变 质岩系的同位素特征一致, 表明靖居正长花岗岩的 形成与古元古代中下地壳岩石在伸展背景下的部分 熔融有关.

研究工作得到了浙江省第七地质大队的支持以及刑光福研究员、徐刚研究员、廖群安教授和赵希林、余明刚 博士等的指导和帮助; 孙洋协助了野外地质调查. 锆石阴极发光及其年代学分析得到余振兵副教授、丁丽雪 及宗克清等的帮助, 微量元素及同位素测试分析得到中国地质大学地质过程与矿产资源国家重点实验室陈 海红老师的指导和王世明、王艳等的帮助; 论文撰写过程中得到张丽娟以及王连训等的帮助, 审稿专家提出 了具有建设性的意见和建议, 在此一并表示衷心的感谢。

\section{参考文献}

1 Han R, Ree J H, Cho D L, et al. SHRIMP U-Pb zircon ages of pyroclastic rocks in the Bansong Group, Taebaeksan Basin, South Korea and their implication for the Mesozoic tectonics. Gondwana Res, 2006, 9: 106-117

2 Zhou X M, Sun T, Shen W Z, et al. Petrogenesis of Mesozoic granitoids and volcanic rocks in South China: A response to tectonic evolution. Episodes, 2006, 29: 26-33

3 陈荣, 邢光福, 杨祝良, 等. 浙东南英安质火山岩早侏罗世锆石 SHRIMP 年龄的首获及其地质意义. 地质论评, 2007, 53: 31-35

4 王强, 赵振华, 简平, 等. 武夷山洋坊霓辉石正长岩的锆石 SHRIMP U-Pb 年龄及其构造意义. 科学通报, 2003, 48: 108-114

5 Wang Q, Li J W, Jian P, et al. Alkaline syenites in eastern Cathaysia (South China): Link to Permian-Triassic transtension. Earth Planet Sci 
Lett, 2005, 230: 339-354

$6 \mathrm{Li} \mathrm{X} \mathrm{H,} \mathrm{Li} \mathrm{Z} \mathrm{X,} \mathrm{Li} \mathrm{W} \mathrm{X,} \mathrm{et} \mathrm{al.} \mathrm{Initiation} \mathrm{of} \mathrm{the} \mathrm{Indosinian} \mathrm{Orogeny} \mathrm{in} \mathrm{South} \mathrm{China:} \mathrm{Evidence} \mathrm{for} \mathrm{a} \mathrm{Permian} \mathrm{Magmatic} \mathrm{Arc} \mathrm{on} \mathrm{Hainan} \mathrm{Island.}$ J Geol, 2006, 114: 341-353

$7 \mathrm{Li} \mathrm{X} \mathrm{H,} \mathrm{Li} \mathrm{Z} \mathrm{X,} \mathrm{Li} \mathrm{W} \mathrm{X,} \mathrm{et} \mathrm{al.} \mathrm{U-Pb} \mathrm{zircon,} \mathrm{geochemical} \mathrm{and} \mathrm{Sr-Nd-Hf} \mathrm{isotopic} \mathrm{constraints} \mathrm{on} \mathrm{age} \mathrm{and} \mathrm{origin} \mathrm{of} \mathrm{Jurassic} \mathrm{I} \mathrm{and} \mathrm{A-type}$ granites from central Guangdong, SE China: A major igneous event in response to foundering of a subdueted flat-slab. Lithos, 2007, 96: 186-204

8 Li X H, Li W X, Li Z X. On the genetic classification and tectonic implications of the Early Yanshanian granitoids in the Nanling Range, South China. Chin Sci Bull, 2007, 52: 1873-1885

9 Li Z X, Li X H. Formation of the 1300-km-wide intracontinental orogen and postorogenic magmatic province in Mesozoic South China: A flat-slab subduction model. Geology, 2007, 35: 179-182

10 周新民. 对华南花岗岩研究的若干思考. 高校地质学报, 2003, 9: 556-565

11 孙涛, 周新民, 陈培荣, 等. 南岭东段中生代强过铝花岗岩成因及其大地构造意义. 中国科学 D 辑: 地球科学, 2003, 33: 1209-1218

12 赵蕾, 于津海, 王丽娟, 等. 红山含黄玉花岗岩的形成时代及其成矿能力分析. 矿床地质, 2006, 25: 672-682

13 王丽娟, 于津海, 徐夕生, 等. 闽西南古田-小陶花岗质杂岩体的形成时代和成因. 岩石学报, 2007, 23: 1470-1484

14 Yu J H, O'Reilly S Y, Zhao L, et al. Origin and evolution of topaz-bearing granites from the Nanling Range, South China: A geochemical and Sr-Nd-Hf isotopic study. Miner Petrol, 2007, 90: 271-300

15 孙涛. 新编华南花岗岩分布图及其说明. 地质通报, 2006, 25: 332-337

16 钟玉芳, 马昌前, 余振兵, 等. 赣西北蒙山岩体的钻石 U-Pb-Hf、地球化学特征及成因. 地球科学一一国地质大学学报, 2011, 36: 703-720

17 于津海, 王丽娟, 魏震洋, 等. 华夏地块显生宙的变质作用期次和特征. 高校地质学报, 2007, 13: 474-483

18 于津海, O'Reilly S Y, 王丽娟, 等. 华夏地块古老物质的发现和前寒武纪地壳的形成. 科学通报, 2007, 52: 11-18

19 王丽娟, 于津海, O'Reilly S Y, 等. 华夏南部可能存在 Grenville 期造山作用: 来自基底变质岩中铅石 U-Pb 定年及 Lu-Hf 同位素信息. 科学通报, 2008, 53: 1680-1692

20 沈渭洲. 华夏地块基底变质岩同位素年龄数据评述. 高校地质学报, 2006, 12: 475-482

21 向华. 浙西南前寒武纪变质基底岩系显生宙变质作用研究. 硕士学位论文. 武汉: 中国地质大学, 2008. 1-56

22 向华, 张利, 周汉文, 等. 浙西南变质基底基性-超基性变质岩锆石 U-Pb 年龄、 $\mathrm{Hf}$ 同位素研究: 华夏地块变质基底对华南印支期造 山的响应. 中国科学 D 辑: 地球科学, 2008, 38: 401-413

23 Liu Y S, Gao S, Hu Z C, et al. Continental and oceanic crust recycling-induced melt-peridotite interactions in the Trans-North China Orogen: $\mathrm{U}-\mathrm{Pb}$ dating, $\mathrm{Hf}$ isotopes and trace elements in zircons from mantle xenoliths. J Petrol, 2010, 51: 537-571

24 Andersen T. Correction of common lead in U-Pb analyses that do not report ${ }^{204} \mathrm{~Pb}$. Chem Geol, 2002, 192: 59-79

25 Ludwig K R. Users manual for Isoplot 3.00: A geochronological toolkit for Microsoft Excel. Berkeley Geochron Cent Spec Pub, 2003, $25-32$

26 Gao S, Zhang B R, Gu X M, et al. Silurian-Devonian provenance changes of South Qinling basins: Implications for accretion of the Yangtze (South China) to the North China craton. Tectonophysics, 1995, 250: 183-197

27 Liu Y S, Zong K Q, Kelemen P B, et al. Geochemistry and magmatic history of eclogites and ultramafic rocks from the Chinese continental scientific drill hole: Subduction and ultrahigh-pressure metamorphism of lower crustal cumulates. Chem Geol, 2008, 247: 133-153

28 Ling W L, Duan R C, Xie X J, et al. Contrasting geochemistry of the Cretaceous volcanic suites in Shandong Province and its implications for the Mesozoic lower crust delamination in the eastern North China craton. Lithos, 2009, 113: 640-658

29 吴元保, 郑永飞. 锆石成因矿物学研究及其对 U-Pb 年龄解释的制约. 科学通报, 2004, 49: 1589-1604

30 Watson E B, Harrison T M. Zircon saturation revisited-temperature and composition effects in a variety of crustal magma types. Earth Planet Sci Lett, 1983, 64: 295-304

31 Middlemost E A K. Naming materials in the magma/igneous rock system. Earth-Sci Rev, 1994, 37: 215-224

32 许冬, 邹婷婷, 田静轩, 等. 广西十万山盆地花岗岩类岩石学及地球化学初步研究. 华南地质与矿产, 2004, 7: 43-49

33 赵蕾, 于津海, 谢磊. 闽西南红山含黄玉浅色花岗岩地球化学特征和成因. 地球化学, 2004, 33: 372-386

34 吴烈勤, 黄国龙, 沈渭洲, 等. 粤北下庄花岗岩地球化学特征与成因研究. 铀矿地质, 2005, 21: 65-71

35 张敏, 陈培荣, 黄国龙, 等. 南岭龙源坝复式岩体的地球化学特征研究. 铀矿地质, 2006, 22: 336-344

36 祁昌实, 邓希光, 李武显, 等. 桂东南大容山-十万大山 $\mathrm{S}$ 型花岗岩带的成因: 地球化学及 Sr-Nd-Hf 同位素制约. 岩石学报, 2007, 23: 221-230

37 陈卫锋, 陈培荣, 周新民, 等. 湖南阳明山岩体的 La-ICP-MS 锆石 U-Pb 定年及成因研究. 地质学报, 2006, 80: 1065-1077 
38 陈卫锋, 陈培荣, 黄宏业, 等. 湖南白马山岩体花岗岩及其包体的年代学和地球化学研究. 中国科学 D 辑: 地球科学, 2007, 37: 873-893

39 凌洪飞, 沈渭洲, 邓平, 等. 粤北帽峰花岗岩体地球化学特征及成因研究. 岩石学报, 2005, 21: 677-687

40 王岳军, 范蔚苔, 梁新权, 等. 湖南印支期花岗岩 SHRIMP 锆石 U-Pb 年龄及其成因启示. 科学通报, 2005, 50: 101-108

41 邱检生, Bia M, 徐夕生, 等. 赣南大吉山五里亭岩体的锆石 ELA-ICP-MS 定年及其与铇成矿关系的新认识. 地质论评, 2004, 50: $125-133$

42 马铁球, 柏道远, 户军, 等. 湘东南茶陵地区锡田岩体锆石 SHRIMP 定年及其地质意义. 地质通报, 2005, 24: 415-419

43 柏道远, 周亮, 马铁球, 等. 湘东南印支期花岗岩成因及构造背景. 岩石矿物学杂志, 2007, 26: 3-18

44 张展适, 华仁民, 邓平, 等. 337 铀矿床帽峰岩体铅石激光探针 U-Pb 法年龄及其地质意义. 铀矿地质, 2007, 23: 310-315

45 于津海, 王丽娟, 王孝否, 等. 赣东南富城杂岩体的地球化学和年代学研究. 岩石学报, 2007, 23: 1441-1456

46 Wang Y J, Fan W M, Sun M, et al. Geochronological, geochemical and geothermal constraints on petrogenesis of the Indosinian peraluminous granites in the South China Block: A case study in the Hunan Province. Lithos, 2007, 96: 475-502

47 Collins W J, Beams S D, White A J R, et al. Nature and origin of A-type granites with particular reference to southeastern Australia. Contrib Mineral Petr, 1982, 80: 189-200

48 Maniar P D, PiccoliI P M. Tectonic discrimination of granitoids. Geol Soc Am Bull, 1989, 101: 635-643

49 Sun S S, McDonough W F. Chemical and isotopic systematics of oceanic basalts: Implications for mantle composition and processes. Geol Soc London Spec Publ, 1989, 42: 313-345

50 沈渭洲, 凌洪飞, 李武显, 等. 中国东南部花岗岩类 Nd-Sr 同位素研究. 高校地质学报, 1999, 5: 23-33

51 沈渭洲, 凌洪飞, 李武显, 等. 中国东南部花岗岩类的 $\mathrm{Nd}$ 模式年龄与地壳演化. 中国科学 D 辑: 地球科学, 2000, 30: 471-478

52 沈渭洲, 凌洪飞, 王德滋, 等. 浙江省中生代火成岩的 Nd-Sr 同位素研究. 地质科学, 1999, 34: 223-232

53 王一先, 赵振华, 包志伟, 等. 浙江花岗岩类地球化学与地壳演化一一I. 显生宙花岗岩类. 地球化学, 1997, 26: 1-15

54 Loiselle M, Wones D. Characteristics and origin of anorogenic granites. Geol Soc Am Bull, 1979, 11: 468

55 Whalen J B, Currie K L, Chappell B W. A-type granites: Geochemical characteristics, discrimination and petrogenesis. Contrib Mineral Petrol, 1987, 95: 407-419

56 汪洋, 邓晋福. 广西南部三叠纪强过铝质火成岩岩石化学特征的动力学意义. 地质地球化学, 2003, 31: 35-42

57 Green T, Pearson N. An experimental study of $\mathrm{Nb}$ and Ta partitioning between Ti-rich minerals and silicate liquids at high pressure and temperature. Geochim Cosmochim Acta, 1987, 51: 55-62

58 Green T. Significance of Nb/Ta as an indicator of geochemical processes in the crust-mantle system. Chem Geol, 1995, 120: 347-359

59 Barth M, McDonough W, Rudnick R. Tracking the budget of Nb and Ta in the continental crust. Chem Geol, 2000, 165: 197-214

$60 \mathrm{Li} \mathrm{X} \mathrm{H,} \mathrm{Li} \mathrm{W} \mathrm{X,} \mathrm{Li} \mathrm{Z} \mathrm{X,} \mathrm{et} \mathrm{al.} \mathrm{Amalgamation} \mathrm{between} \mathrm{the} \mathrm{Yangtze} \mathrm{and} \mathrm{Cathaysia} \mathrm{Blocks} \mathrm{in} \mathrm{South} \mathrm{China:} \mathrm{Constraints} \mathrm{from} \mathrm{SHRIMP} \mathrm{U-Pb}$ zircon ages, geochemistry and Nd-Hf isotopes of the Shuangxiwu volcanic rocks. Precambrian Res, 2009, 174: 117-128

61 陈志洪, 郭坤一, 董永观, 等. 江山-绍兴拼合带平水段可能存在新元古代早期板片窗岩浆活动: 来自锆石 LA-ICP-MS 年代学和地球 化学的证据. 中国科学 D 辑: 地球科学, 2009, 39: 994-1008

62 Li W X, Li X H, Li Z X. Neoproterozoic bimodal magmatism in the Cathaysia Block of South China and its tectonic significance. Precambrian Res, 2005, 136: 51-66

63 Li X H, Sun M, Wei G, et al. Geochemical and Sm-Nd isotopic study of amphibolites in the Cathaysia Block, SE China: Evidence for extremely depleted mantle in the Paleoproterozoic. Precambrian Res, 2000, 102: 251-262

64 付树超, 陈觉民, 林文生. 福建建宁西部上太古界天井坪组 $\left(\mathrm{Ar}_{2} t\right)$ 地质特征. 福建地质, 1991, 10: 103-112

65 李曙光, 陈移之, 葛宁洁, 等. 浙西南八都群变质火山岩系及变晶糜棱岩的同位素年龄及其构造意义. 岩石学报, 1996, 12: 79-87

66 杨杰东, 徐士进, 王银喜, 等. 浙江龙泉八都群斜长角闪岩的 Sm-Nd 和 Rb-Sr 年龄测定及其意义. 地球化学, 1994, 23: 25-31

67 陈多福, 李献华, 潘晶铭, 等. 浙江景宁鹤溪群斜长角闪岩变质新生锆石特征、离子探针(SHRIMP)U-Pb 年龄及地质意义. 矿物学报, 1998, 18: 396-400

68 李献华, 李武显. 华南早中生代岩浆作用的时代、成因及构造意义. 2004 年全国岩石学与地球动力学研讨会. 中国海南海口, 2004. 107-108

69 Peng B X, Wang Y J, Fan W M, et al. LA-ICP-MS Zircon U-Pb Dating for three Indosinian granitic plutons from central Hunan and western Guangdong Provinces and its petrogenetic implications. Acta Geol Sin, 2006, 80: 660-669

70 丁兴, 陈培荣, 陈卫锋, 等. 湖南沩山花岗岩中铅石 LA-ICP-MS U-Pb 定年: 成岩启示和意义. 中国科学 D 辑: 地球科学, 2005, 35: 606-616

71 续海金, 马昌前, 钟玉芳, 等. 湖南桃江、大神山花岗岩的锆石 SHRIMP 定年: 扬子与华夏拼合的时间下限. 2004 年全国岩石学与地 
球动力学研讨会. 中国海南海口, 2004.312-314

72 李献华. 万洋山-诸广山花岗岩复式岩基的岩浆活动时代与地壳运动. 中国科学 B 辑, 1990, 7: 77-85

73 张文兰, 华仁民, 王汝成, 等. 江西大吉山五里亭花岗岩单颗粒锆石 U-Pb 同位素年龄及其地质意义探讨. 地质学报, 2004, 78: 352-358

74 张敏, 陈培荣, 黄国龙, 等. 南岭东段龙源坝复式岩体 La-ICP-MS 锆石 U-Pb 年龄及其地质意义. 地质学报, 2006, 80: 984-994

75 孙立强, 凌洪飞, 沈渭洲, 等. 南岭地区油山岩体和坪田岩体形成年龄及其地质意义. 高校地质学报, 2010, 16: 186-197

76 董晨阳, 赵葵东, 蒋少涌, 等. 赣南白面石铀矿区花岗岩的锆石年代学、地球化学及成因研究. 高校地质学报, 2010, 16: 149-160

77 陈培荣, 张敏, 陈卫峰. 九峰-诸广山岩体. 周新民, 主编. 南岭地区晚中生代花岗岩成因与岩石圈动力学演化. 北京: 科学出版社, 2007. 533-549

78 徐夕生, 邓平, O'Reilly S Y, 等. 华南贵东杂岩体单颗粒锆石激光探针 ICPMS U-Pb 定年及其成岩意义. 科学通报, 2003, 48: 1328-1334

79 邓希光, 陈志刚, 李献华, 等. 桂东南地区大容山-十万大山花岗岩带 SHRIMP 锆石 U-Pb 定年. 地质论评, 2004, 50: 91-97

80 赵葵东, 蒋少涌, 孙涛, 等. 南岭西段印支期花岗岩 Hf-Nd 同位素解耦现象及岩石成因意义. 2006 年全国岩石学与地球动力学研讨 会. 中国江苏南京, 2006. 435

81 邵建国, 彭少梅. 云开地区前海西期构造演化的同位素年代学研究. 广东地质, 1995, 10: 41-50

82 邵建国, 彭少梅. 云开地块周边断裂带 ${ }^{40} \mathrm{Ar}{ }^{36} \mathrm{Ar}-{ }^{39} \mathrm{Ar}{ }^{36} \mathrm{Ar}$ 等时线定年. 广东地质, 1995, 10: 34-40

83 彭少梅, 伍广宇. 云开地块的构造演化史及其动力学特征. 广东地质, 1996, 11: 39-46

84 Liang X Q, Li X H. Late Permian to Middle Triassic sedimentary records in Shiwandashan Basin: Implication for the Indosinian Yunkai Orogenic Belt, South China. Sediment Geol, 2005, 177: 297-320

85 梁新权, 李献华, 丘元禧, 等. 华南印支期碰撞造山一一万大山盆地构造和沉积学证据. 大地构造与成矿学, 2005, 29: 99-112

86 Wang Y J, Zhang Y H, Fan W M, et al. Structural signatures and ${ }^{40} \mathrm{Ar}^{39} \mathrm{Ar}^{39}$ geochronology of the Indosinian Xuefengshan tectonic belt, South China Block. J Struct Geol, 2005, 27: 985-998

87 Wang Y J, Fan W M, Zhao G C, et al. Zircon U-Pb geochronology of gneissic rocks in the Yunkai massif and its implications on the Caledonian event in the South China Block. Gondwana Res, 2007, 12: 404-416 